\title{
Editor's Introduction: Feminization, Theorizing, Politics and Pedagogy
}

\section{Lawrence T. Nichols ${ }^{1}$}

Published online: 5 March 2019

C) Springer Science+Business Media, LLC, part of Springer Nature 2019

In this issue we present five papers that range widely across current controversies and historical contributions, as well as across national boundaries, approaches to theory and classroom pedagogies. There is likewise a spectrum of methodologies, including archival documentary research, historical discourse analysis, latent semantic analysis, surveys and causal path modeling.

The initial article, by Christine Bucior and Alan Sica, builds upon the analysis presented in this journal in 2007 by DiFuccia, Pelton and Sica., which examined the shift in sociology in the United States from a male-dominated field to one in which women and their interests attained primacy. Bucior and Sica, focusing especially on the most recent decade, report a series of empirical findings regarding both demographics and substantive interests. They present descriptive statistics on female representation in the fifty highest-ranked sociology departments in the U.S. and they likewise provide longitudinal data on the percentages of female and male members in the American Sociological Association. Bucior and Sica then proceed to a discussion of important differences between course offerings in "highly feminized" and "highly masculine" departments of sociology, as well as the relative prevalence of "female" and "male" dissertation topics. The authors" interest is portraiture, rather than explanation, and they offer their work as a resource that others might build upon.

Jacob Heller probes the issue of why sociologists generally regard gender as a social construct, but consider sex to be an unconstructed, biological property of persons. The author undertakes an historical analysis of professional discourse regarding foundational "sex chromosome" discoveries in 1905, and he argues that what researchers of that era referred to as "sex" was actually strongly influenced by gender norms of the day. Heller concludes with the suggestion that sociologists re-examine what has been regarded as settled fact, namely, that $\mathrm{X}$ and $\mathrm{Y}$ chromosomes determine sex, and that they reconsider the ways in which "sex" has been, and continues to be, socially constructed.

Konstantinos Zougris next offers a comparative analysis of national sociologies in the United States and Britain. The author is especially interested in "topic structures" and the "topical clusters" that create a chasm between sociologists on opposite sides of the Atlantic.

Lawrence T. Nichols

lnichol2@wvu.edu

1 West Virginia University, Morgantown, WV, USA 
Drawing upon more than ten thousand abstracts in eight selected journals, Zougris uses latent semantic analysis to identify significant differences, by nation, in publication preferences with regard to specialty fields (e.g., health, social networks, income inequality). The author then discusses a "fundamental epistemological divide" based on an overarching preference for theory or for empirical methods in the respective homelands. In closing, Zougris reports commonalities that might bridge the current separation.

Richard Swedberg then addresses the perennial issue of how raw data become sociological knowledge. Swedberg's particular focus is a two-semester course in "theorizing" that Robert K. Merton taught at Columbia University for slightly more than a decade from the early 1940s into the 1950s. While Merton's writings on the mutual influence of theory and research are widely recognized, his efforts in the classroom to train students to "theorize" have remained generally unknown. Swedberg credits Merton as being the first to identify theorizing as a distinct area of study. As the author reports, while working on his larger project of the "codification" of sociological knowledge, Merton also sought to develop a distinctive toolkit for theorizing. The key insight, in Swedberg's judgment, is that only through the medium of theory can empirical data "become sociology."

Charles Crothers likewise focuses on Merton, for the purpose of developing a systematic and updated bibliography. Building on earlier efforts by scholars in the U.S. and France, Crothers seeks to provide a relatively comprehensive listing of writings about Merton over the past couple of decades. The author also attempts to identify significant patterns in recent responses to Merton's wide-ranging publications. Crothers concludes that interest in Merton not only persists but is actually increasing internationally, and that Merton's works will continue to inspire sociological work in many nations.

Jeremiah Wills, Zachary Brewster and Gerald Nowak, finally, provide an empirical examination of students' perceptions of political bias among their professors, according to students' religious orientations. The authors focus in particular on undergraduates enrolled in sociology courses, basing their analysis on responses in survey data. They approach religiosity as a foundational element in political conservatism, and they present a causal path model of how religiosity, along with ideological distance between faculty and students and a preexisting skepticism toward science among students, affects both students' perceptions of bias and their reactions to it. Wills, Brewster and Nowak conclude with a discussion of the challenge for sociologists "to develop pedagogical approaches that translate into learning for students of all political and religious traditions".

Publisher's Note Springer Nature remains neutral with regard to jurisdictional claims in published maps and institutional affiliations. 